\title{
Extensão e Compromisso Social: 30 anos do Núcleo de Estudos da Terceira Idade (NETI)
}

Flora Moritz da Silva floramds@gmail.com

Pedro Antônio de Melo pedromelo@inpeau.ufsc.br

Rudimar Antunes da Rocha rrudimar@hotmail.com

Palavras-chave: Compromisso Social. Extensão. Terceira idade. Universidade.

\section{Resumo}

Nas próximas décadas, quase um terço da população brasileira será idosa, sendo relevante compreender a situação da terceira idade para assegurar a cidadania dos idosos e de toda a sociedade. O NETI foi um dos pioneiros no Brasil a lutar pela terceira idade nas universidades brasileiras, e o presente trabalho visa conhecê-lo desde o seu surgimento, para compreender as práticas de compromisso social ali desenvolvidas. Para tanto, resgataram-se os conceitos de terceira idade, universidade pública, extensão e compromisso social e desenvolveu-se uma pesquisa qualitativo-descritiva, através de bibliografias, documentos institucionais e entrevistas semiestruturadas com coordenadora, fundadora e representações estudantis do núcleo, e acompanhamento do Curso Previdência e Cidadania em 2012/2. Foi encontrado um núcleo iniciado por meio de pesquisa das aspirações da comunidade e levantado junto aos alunos voluntários. A série de cursos abrangendo política, previdência e cidadania a partir de 2011 como resposta à demanda dos alunos mostra que o núcleo continua dialogando com todos os seus membros. As práticas desenvolvidas relevam um alto grau de compromisso social, em que o foco é a emancipação e a realização dos sujeitos, sendo de grande valia à sociedade.

\section{Extension and Social Commitment: 30 years of the Senior Center of Study (NETI)}

Key words: Social Commitment. Extension. Third age. University.

\section{Abstract}

In the coming decades almost a third of the population will be elderly, being relevant to understand the situation of the elderly to ensure the citizenship of the elderly and of the whole society. The NETI was a pioneer in Brazil to fight for the Third Age in Brazilian's universities and the present study aims to know it 


\section{Extensio $\mid$ Artigo}

from its inception, to understand the practices of social commitment developed there. Therefore, rescued the concepts of third age, public university, extension and social commitment and developed a qualitative descriptive research through bibliographies, documents and semi-structured interviews with institutional coordinator, founder, and student representatives of the Center of Study, and monitoring Security and Citizenship Course in 2012/2. Was found a Center of Study initiated through research aspirations of the community and built with volunteer students. A series of courses covering political, security and citizenship from 2011 in response to demand from students shows that the Center of Study continues to talk to all its members. Practices developed showed a high degree of social commitment, in which the focus is on empowerment and achievement of subject, being of great value to society.

\section{INTRODUÇÃO}

O século 20 caracterizou-se por grandes mudanças sociais, que trouxeram avanços tecnológicos e na área da saúde, mas também novos desafios. A expectativa de vida do ser humano aumentou cerca de 30 anos ao longo do século, trazendo uma revolução demográfica, que clama por uma nova visão da saúde pública, de questões previdenciárias e, principalmente, uma nova visão do envelhecer, sem estereótipos, com independência e qualidade de vida, já que em 2050, ou seja, nas próximas quatro décadas, quase $30 \%$ da população brasileira será idosa (BANCO MUNDIAL, 2011).

Essa revolução coloca aos especialistas, homens públicos e coletividades um enorme desafio social, que demanda por pesquisas e análises para definir da melhor forma as políticas públicas de prevenção de saúde no envelhecimento (VERAS; CALDAS, 2004). Vale destacar que a saúde não deve ser pensada apenas do ponto de vista fisiológico.

Se, em menos de quatro décadas, quase um terço da população brasileira será idosa, é relevante investigar questões que vão além do aumento da sobrevida, compreender a situação da terceira idade, para assegurar a cidadania dos idosos e o melhor para toda a sociedade, visto que as próximas gerações também partilharão desses avanços. Dessa forma, percebe-se a importância de entender a dinâmica atual de envelhecimento que nossa sociedade desenvolve e como os idosos desenvolverão atitudes participativas e de grande valia social.

Nessa conjuntura, a universidade tem um papel importante na promoção da emancipação humana. Há um reconhecimento do papel estratégico das universidades, em especial do setor público, objetivando colocar o ensino, a pesquisa e a extensão a serviço do desenvolvimento social, econômico e cultural da nação (RISTOFF, 2006). Não se trata de prescindir da ação da universidade, mas de ressignificar a contribuição universitária por meio da gestão social e da cidadania, promovendo, concomitantemente, sua missão em prol da ciência, criação do conhecimento e da educação.

Na década de 1970 na França, dentro da Universidade de Toulouse, um Professor chamado Pierre Vellas inicia um projeto voltado para modificar a imagem social do idoso, procurando a integração entre as gerações. Foi o pioneiro das Universidades da Terceira Idade, experiência que deu certo e espalhou-se por diversos países, em distintos modelos.

O Professor Vellas fundou também a Associação Internacional das Universidades da Terceira Idade (AIU3I), que é uma federação de universidades da terceira idade, e outras instituições com outros títulos, porém com objetivos semelhantes. Essas instituições focam-se, sobretudo, no crescimento pessoal do idoso 
e no modo como ele desenvolverá, de forma livre e autônoma, seus papeis na sociedade (AIU3I, 2012).

Na Universidade Federal de Santa Catarina (UFSC), o Núcleo de Estudos da Terceira Idade (NETI) completou 30 anos em 2012, com a missão de:

Redescobrir, recriar de forma integrada, sistematizar e socializar o conhecimento de gerontologia, desenvolvendo atividades de promover as pessoas da terceira idade no meio acadêmico e comunitário, como sujeitos em transformação e transformadores (NETI, 2013, s/p.).

Como o núcleo traz consigo uma proposta de promover as pessoas da terceira idade como "sujeitos em transformação e transformadores", este artigo busca compreender as práticas de compromisso social do Núcleo de Estudos da Terceira Idade da Universidade Federal de Santa Catarina.

O NETI foi um dos pioneiros no trabalho com a terceira idade entre as universidades públicas brasileiras e atualmente oferece amplo leque de atividades para atender a diferentes demandas. A importância de uma pesquisa com a população idosa sobre o ponto de vista do compromisso social, do qual a cidadania é um ponto chave, justifica-se, pois investiga a contribuição para a transformação do indivíduo em direção ao enfrentamento das barreiras sociais e preconceitos existentes em nossa sociedade. Para Tenório (2010), uma relação reflexiva e dialógica se trava e os idosos redescobrem sua imagem como cidadãos, sujeitos que escrevem sua história. Assim, espera-se que este estudo possa contribuir nas pesquisas e na gestão de Universidades da Terceira Idade, em geral, e do NETI, em particular. Para tanto, será contextualizado o processo de envelhecimento populacional no Brasil, uma breve noção do surgimento das Universidades da Terceira Idade, a universidade, sua função social, a extensão, a responsabilidade e o compromisso social. Logo após, serão apresentados os procedimentos metodológicos que operacionalizaram o objetivo da pesquisa e, por fim, seus resultados e conclusões da pesquisa.

\section{TERCEIRA IDADE, UNIVERSIDADE PÚBLICA, EXTENSÃO E COMPROMISSO SOCIAL}

O processo de envelhecimento populacional não resulta principalmente do declínio da mortalidade. Nasri (2008) explica que a causa principal é o declínio da fecundidade, já que o envelhecimento populacional trata-se da relação do número de idosos com a população absoluta. Dessa forma, a população envelhece à medida que aumenta a proporção de idosos em relação à proporção de jovens.

A estrutura etária da população brasileira sofreu intensa mudança, primeiro com a queda dos níveis de mortalidade e, em seguida, com o declínio dos níveis de fecundidade. Se o declínio da mortalidade infantil inicialmente acarretou um contingente de jovens, associado à diminuição da fecundidade resultou em um crescimento da população adulta e, consequentemente, um aumento da população idosa nos anos noventa.

Para os próximos 40 anos, a previsão é um aumento substancial no número de idosos e, principalmente, o envelhecimento populacional. O portal da saúde do Governo Federal (BRASIL, 2012) noticia que, em 2050, o Brasil terá 63 milhões de idosos: "se em 1980 eram 10 idosos para cada 100 jovens, em 2050 serão 172 idosos para cada 100 jovens”. A pirâmide etária se inverterá devido à baixa capacidade de renovação. 


\section{Extensio $\mid$ Artigo}

A população idosa apresenta grande diversidade entre si e em relação aos demais grupos etários. Para compreendê-la, são necessários vários enfoques, necessitando de uma visão interdisciplinar: as diversas áreas devem ser conectadas (RICCI et al., 2006).

As representações da velhice são construções sociais, em permanente mudança. Estão relacionadas à posição remetida a pessoas idosas na sociedade, não traduzindo necessariamente nem a idade cronológica, nem as mudanças físicas, mas, sobretudo, as “[...] necessidades econômicas e políticas inscritas na cadeia de mudança, impondo às pessoas idosas desafios em termos de comportamentos, atitudes e valores” (DANIEL, p. 119, 2006).

Na segunda metade do século XX, muitas conquistas dos idosos permitiram a alguns viver de forma distinta aos estereótipos de fragilidade associados a essa faixa etária. Surge o termo terceira idade e, com ele, uma nova postura entre os que têm condições de desfrutá-la.

A partir de um movimento dentro da Universidade de Toulouse que o termo "terceira idade" foi cunhado, expressão que remete a um conceito de envelhecimento ativo. Conforme Frutuoso (1999, p. 35), a expressão "terceira idade" não deve ser confundida com velhice. "Surgida na França, no final dos anos 60, refere-se a uma emergente realidade do envelhecer, ligada a um novo tempo de lazer e não mais associada à miséria, doença e decadência, o que geral ocorria após a vida profissional ativa”. Assim, o termo assume a conotação de realização pessoal, uma divisão etária na qual as pessoas têm autonomia com saúde e qualidade de vida.

A expressão terceira idade, originada com a implementação das Universités du Troisième Âge, se popularizou rapidamente no Brasil. Os primeiros gerontólogos brasileiros foram formados na França (DEBERT, 1994). Veras e Caldas (2004) relatam que o movimento Universidade da Terceira Idade vem apresentando um substancial incremento desde 1970, a partir de uma ação multidisciplinar para inserir o idoso como cidadão ativo na sociedade. Já em 2004, os autores afirmavam existir no Brasil pelo menos 150 programas desse tipo.

Novos significados são conferidos aos estágios mais avançados da vida, podendo agora também serem vistos como momentos para novas conquistas. As experiências e conhecimentos acumulados proporcionariam aos idosos as chances de descobrir novas identidades, concretizar projetos abandonados em outros estágios da vida, constituir relacionamentos mais proveitosos com todas as gerações, permitindo que as experiências de envelhecimento exitosas possam ser vividas coletivamente. Nos últimos anos, tem aumentado no Brasil o número de universidades e grupos de convivência da terceira idade que têm promovido a redefinição de valores, atitudes e comportamentos das pessoas envolvidas nesses grupos (DEBERT, 1997).

Dal Rio (2009) afirma que o público procura as universidades da terceira idade visando a uma convivência social mais ativa, novos conhecimentos e novos meios de se expressar, anseios característicos dessa fase da vida.

Segundo a Associação Internacional das Universidades da Terceira Idade (AIU3A, 2012), a primeira Universidade da Terceira Idade foi fundada em Toulouse em 1973, na Universidade de Ciências Sociais, pelo Professor Pierre Vellas da Faculdade de Ciências e Direito Econômico. O projeto visava oferecer aos idosos um programa de atividades que satisfizesse as condições, necessidades e aspirações nessa idade da vida. Dal Rio (2009) afirma que, a partir da década de 1980, as universidades brasileiras começaram a dar espaço às Universidades da Terceira Idade. 
Debert (1996) relata o êxito mobilizador dos programas para a terceira idade. Em tais programas, os saberes acumulados propiciariam que o idoso explore novas identidades, abandonando a ideia do idoso como um processo contínuo de perdas. No entanto, a autora afirma que tal êxito é proporcional à fragilidade dos mecanismos existentes para lidar com as dificuldades da velhice avançada. A imagem do envelhecimento bem-sucedido não dispõe de instrumentos adequados para enfrentar os problemas decorrentes da perda de habilidades cognitivas, necessárias para que uma pessoa seja reconhecida como autônoma e capaz de exercitar seus direitos de cidadania plenamente (DEBERT, 1997). Assim, mais do que um momento de aprendizado lúdico e de convivência, é importante analisar as Universidades da Terceira Idade sobre o prisma da cidadania, envolvendo a todos os atores sociais com inclusão.

\subsection{Universidade Pública e sua Função Social}

A universidade é uma instituição secular, com diferentes características ao longo da história. No Brasil, as universidades, segundo o artigo 207 da Constituição Federal, "[...] gozam de autonomia didático-científica, administrativa e de gestão financeira e patrimonial, e obedecerão ao princípio de indissociabilidade entre ensino, pesquisa e extensão" (BRASIL, 1988).

Por ser uma instituição social, a universidade exprime a estrutura e a forma de funcionamento da sociedade. Assim, dentro da instituição, observam-se projetos e opiniões conflitantes que refletem divisões e contradições da sociedade. Essa relação entre sociedade e universidade, que ilustra o fato de que a universidade pública foi uma instituição social desde seu surgimento, é, conforme Chauí (2003, p. 5),

[...] uma ação social, uma prática social fundada no reconhecimento público de sua legitimidade e de suas atribuições, num princípio de diferenciação, que lhe confere autonomia perante outras instituições sociais, e estruturada por ordenamentos, regras, normas e valores de reconhecimento e legitimidade internos a ela. A legitimidade da universidade moderna fundou-se na conquista da ideia de autonomia do saber em face da religião e do Estado, portanto, na ideia de um conhecimento guiado por sua própria lógica, por necessidades imanentes a ele, tanto do ponto de vista de sua invenção ou descoberta como de sua transmissão.

Chauí (2003) alerta, entretanto, que as mudanças e pressões sofridas na universidade, nos últimos anos, transformaram-na em uma universidade operacional, reduzindo-a a uma organização em vez de uma instituição, por "[...] definir-se por uma prática social determinada de acordo com sua instrumentalidade" (CHAUÍ, p.6, 2003). Assim, a universidade se lança na fragmentação competitiva, produzindo conhecimento destinado à apropriação privada.

Em defesa de uma instituição universitária pública, Pacheco (2006) ressalta que a universidade não é pública por ser gratuita, mas porque sua produção teórica e científica deve ser apropriada publicamente.

Goergen (2006) confia na importância da universidade para o desenvolvimento da sociedade, ainda que a conexão entre ciência e desenvolvimento possa ser mal entendida em contextos de atraso cultural e verbas reduzidas, como o brasileiro. Nesse ambiente, a universidade, pelo calibre de recursos que consome e dos temas teóricos sem aplicação prática imediata que se ocupa, pode ser estigmatizada como uma instituição de luxo. Em muitas ocasiões, procura-se superar essa dificuldade buscando uma relação quase mecânica entre as atividades acadêmicas e a sociedade, incorrendo, assim, na ambivalência de operacionalizar uma instituição que, por sua natureza, deve se preservar autônoma e crítica. 
Em 1994, Santos (2008) falava dos desafios feitos à universidade no século XX, os quais o autor afirma que se agravaram nos últimos tempos, como ele previa. As reflexões de Goergen podem ser associadas ao que Santos (2008, p.14) chama de "crise institucional da universidade”, resultante dessa contradição da “[...] reivindicação da autonomia na definição de valores e objetivos da universidade e a pressão crescente de submeter esta última a critérios de eficácia e de produtividade de natureza empresarial ou de responsabilidade social".

Goergen (2006) acusa que esse tipo de política que instrumentaliza a universidade visa privilegiar atividades com aplicação prática direta ao contexto social para superação das carências imediatas ali encontradas. Conforme essa estratégia, os recursos devem gerar produtos úteis, não raro, no sentido de preencher responsabilidades a princípio pertinentes a outros setores. Essa expectativa demanda um modelo de instituição operacional que desconsidera aspectos importantes da atividade acadêmica que não podem ser traduzidos em produtos imediatamente transferíveis ao plano prático. Nestes casos encontra-se, por exemplo, as pesquisas básicas, sem aplicação prática imediata. Não há relação direta e mecânica entre atividades acadêmicas e suas implicações sociais. Isso não significa dizer que a universidade não deve comprometer-se com a sociedade, mas sim que não deve ser refém do imediatismo.

Para que a universidade pública seja tomada por um novo olhar, primeiramente, o Estado deve tomar a educação como um investimento social e público e um direito de todos, "[...] para assegurar a concreticidade dos direitos sociais, entre os quais se encontra a educação" (CHAUÍ, p.12, 2003). Por meio da destinação dos recursos públicos aos direitos sociais que se mensura a democratização do Estado e da universidade.

Ao refletir sobre a transformação da universidade pública sob a perspectiva da democratização e formação, Chauí (2003) enfatiza alguns pontos necessários para tal mudança, os quais se destacam nesta pesquisa: romper com modelos que tentem resolver os problemas da educação superior brasileira com algum tipo de privatização da educação superior, incentivando com governamentais recursos de grupos privados; autonomia universitária definida pelo direito de determinar suas normas de formação, pesquisa e docência, com autonomia intelectual e não critérios produtivistas; liberdade para adotar perspectiva crítica; e diálogo e transparência com a sociedade civil e os agentes do Estado.

É importante ressaltar que a universidade pública não é uma instituição alheia à sociedade, ao Estado e mesmo ao mercado. Ela é um órgão da administração pública indireta, uma autarquia, portanto com autonomia; ela pertence à sociedade e deve estar orientada para atender às suas demandas, particularmente, às relacionadas aos processos de superação das iniquidades dominantes na sociedade de mercado, dialogando com o mercado, mas mantendo sua perspectiva crítica e não sendo ditada por ele.

\subsection{Extensão, Responsabilidade e Compromisso Social}

O princípio da indissociabilidade, colocado no artigo 207 da Constituição Federal Brasileira, fala de três funções básicas para uma Instituição de Ensino Superior ser considerada uma universidade: ensino, pesquisa e extensão, sendo a extensão, no histórico da instituição "universidade”, em termos cronológicos, a última das funções a ser incorporada, formando esse tripé.

Novo e Melo (2004) explicam que a extensão foi atribuída à universidade visando viabilizar sua inte- 
ração com a sociedade, sendo essa função, exercida juntamente com o ensino e a pesquisa, capaz de operacionalizar a relação entre teoria e prática, promovendo a troca entre os saberes acadêmico e popular.

Extensão universitária é o processo educativo, cultural e científico que articula o ensino e a pesquisa de forma indissociável viabilizando a relação transformadora entre universidade e sociedade (PLANO NACIONAL DE EXTENSÃO UNIVERSITÁRIA, 2001). É uma via de mão dupla: a comunidade acadêmica encontra na sociedade a oportunidade de praticar os conhecimentos acadêmicos e retorna com o aprendizado daquela comunidade. A troca de saberes sistematizados, acadêmico e popular trará a produção do conhecimento resultante do confronto com a realidade regional, a democratização do conhecimento acadêmico e a participação da comunidade na atuação da universidade. É um trabalho interdisciplinar que favorece a visão integrada do social (NOGUEIRA, 2000).

Cruz et al. (2010) constroem, a partir da extensão e da transferência de tecnologia social, uma abordagem de responsabilidade social, levando em consideração os benefícios para a IES, os participantes e a sociedade. Transferência de tecnologia social aqui é descrito como "[...] conhecimento em projetos comunitários” (CRUZ et al, 2010, p.01), empoderar as representações coletivas por ferramentas procedentes da administração.

Responsabilidade Social é um termo recente, popularizado na segunda metade do Século XX e muito vinculado a organizações: a partir dos anos 1950, a sociedade começa a questionar sobre as responsabilidades das empresas, e o significado da expressão, a partir de então, vem sendo debatido e revisado (KARKOTLI, 2006). Não há uma única definição, mas a prática da responsabilidade social não é sinônimo de filantropia: ela vai muito além. Silva (2010) constatou que, ainda que o termo responsabilidade social abranja diversas variáveis e visões, alguns aspectos em relação ao conceito se repetem em muitos dos estudos sobre o tema. Esse mesmo autor destacou que

[...] é mais do que simplesmente cumprir a legislação e comprometer-se com o desenvolvimento econômico da organização; é um conceito transversal, que permeia toda a organização e a todos os que, de alguma forma são afetados pelas atividades da mesma; envolve conceitos como responsabilidade para com o ambiente, para com a sociedade, transparência, diálogo entre as partes interessadas e o bom governo; compreensão que os compromissos vão além da cadeia produtiva, para com toda a sociedade, expressos por meio de atos que afetem positivamente; gestão ética; estabelecimento de metas que impulsionem o desenvolvimento sustentável da sociedade; redução de desigualdades com ênfase na cidadania (SILVA, 2010, p. 153).

Assim, responsabilidade social é um conceito amplo que deve estar na agenda organizacional de toda instituição, mas a universidade não é uma instituição peculiar e não deve ser compreendida como uma organização empresarial. Como uma instituição com função social já intrínseca, alguns autores defendem que, mais do que socialmente responsável, é necessário que ela esteja socialmente comprometida (SILVA, 2010).

Freire (1979, p. 19) reflete sobre o ato de comprometer-se. Para um ato comprometido, é necessário ser capaz de atuar e refletir. Há um compromisso com a humanização do homem, que implica em uma responsabilidade histórica que não pode ser realizada senão através da “[...] realidade concreta, onde se encontram os homens concretos". O ato de comprometer-se é consciente, não podendo ser neutro: a neutralidade é o medo de revelar o compromisso. O verdadeiro compromisso é sempre solidário, nunca unilateral, pois, ao se comprometer com um sujeito ativo, torna-se um encontro dinâmico e solidário: ao alcançar aqueles com os quais se compromete, há um retorno. É, portanto, uma via de mão dupla. O autor ainda defende que o compromisso só e válido quando carregado de humanismo, que só é consciente quando fundamentado 
cientificamente.

A expressão "compromisso social” é atribuída ao compromisso da universidade para com a sociedade, visto que uma instituição que tem como finalidade o ensino, a pesquisa e a extensão já exerce uma grande responsabilidade social. Comprometimento tem uma conotação de um envolvimento maior ainda. De tal modo, discorrer sobre o compromisso social da universidade significa falar de seus deveres e obrigações, de sua função, das incumbências inerentes à natureza institucional das universidades.

A conceituação divulgada pelos pró-reitores no Plano Nacional de Extensão Universitária (2001) proclama uma postura da universidade diante da sociedade na qual se insere: ao afirmar que a extensão se coloca como prática acadêmica que visa interligar a universidade em suas atividades de pesquisa e ensino, com as demandas da sociedade, reafirma o compromisso social da universidade como configuração de inserção nas ações de promoção e garantia dos valores democráticos, de igualdade e desenvolvimento social.

Conforme Novo e Melo (2004), com a função extensão, passa a ser considerado o compromisso social da universidade, que precisará encontrar-se empenhada no equacionamento das questões que afligem a maioria da população, dirigindo seus interesses para as grandes questões sociais do país e àquelas demandadas pelas comunidades regionais e locais.

A verdadeira proposta de extensão, portanto, está articulada com o ensino e a pesquisa, levando bi ou multilateralmente o conhecimento, da universidade à comunidade, e vice-versa, com a finalidade de promover autonomia e discernimento, tanto aos universitários, que ganham outra visão do mundo, experiências e informações ricas, que não poderiam ser captadas em uma sala de aula comum; quanto à comunidade, beneficiada com determinado projeto. Essa extensão pode ser considerada como uma atitude de transformação, de capacidades e aprendizados que retroalimentam o processo e a todos os atores envolvidos, além de fomentar a emancipação em vez da dependência, estando intimamente atrelada à responsabilidade da universidade para com a sociedade, ou seja, seu compromisso social.

\section{PROCEDIMENTOS METODOLÓGICOSx}

De acordo com Lakatos e Marconi (1995), além da fundamentação teórica, um trabalho científico necessita basear-se em procedimentos metodológicos adequados, de forma que trate as categorias analíticas, os conceitos e os fenômenos pesquisados com consistência e coerência, explicando detalhadamente como será realizada a pesquisa.

Este estudo é uma pesquisa teórica, caracterizada como aquele que articula conceitos e sistematiza a produção de uma área de conhecimento, com o objetivo de criar novos questionamentos, incorporando e aprofundando o estado da arte de determinado assunto (MINAYO, 2002). A pesquisa utiliza a abordagem qualitativo-descritiva, pois não busca a mensuração dos eventos estudados, nem emprega instrumental estatístico na análise dos dados, mas os dados são adquiridos pelo contato do pesquisador com a situação estudada, procurando a compreensão dos fenômenos segundo a perspectiva dos sujeitos e descrevê-los sem manipular ou interferir na realidade (BECKER, 1997).

Em relação aos meios, a pesquisa é de campo, documental e bibliográfica. É considerada de campo porque a investigação empírica foi a campo para entrevistar envolvidos com as Universidades da Terceira Idade. É documental, pois se utilizou de documentos da UFSC e do NETI e bibliográfica porque, antes da saída de campo, buscou-se fundamentação em assuntos pertinentes à temática. 
Além da pesquisa documental, foram realizadas entrevistas semiestruturadas no segundo semestre de 2012, com a coordenadora do NETI, uma das fundadoras, a presidente do Centro de Estudantes do NETI (CENETI), e o presidente da Associação de Monitores da Ação Gerontológica (AMAG). As entrevistas foram realizadas nas respectivas salas dos entrevistados, dentro do NETI, e em uma sala de estudos do núcleo para os entrevistados que não tinham uma sala específica. Todas as entrevistas foram gravadas, com o consentimento dos entrevistados. Acrescenta-se ainda a observação direta, realizada pelo contato direto do pesquisador com o fenômeno observado, para "[...] recolher as ações dos atores em seu contexto natural, a partir de sua perspectiva e seus pontos de vista” (CHIZZOTTI, 1995, p. 90). Além de diversas visitas, durante o segundo semestre de 2012, as aulas do curso Previdência e Cidadania, oferecido quinzenalmente às quintas-feiras no NETI, foram acompanhadas pela pesquisadora.

Para análise dos dados, utilizou-se a análise documental, que abrange a investigação de documentos internos organizacionais ou externos, e análise das entrevistas, transcritas e analisadas mediante os dados levantados.

Como auxiliar da análise, foi considerado o modelo adaptado por Silva (2013), que expõe categorias de análise para projetos de extensão, expostas no Quadro 1. Esse direcionamento ajudou no roteiro das entrevistas semiestruturadas.

Quadro 1 - Categorias de análises dos projetos

\begin{tabular}{|c|c|c|}
\hline Categorias de Análise & Gestão Burocrática & Compromisso Social \\
\hline Metodologia & Clientelista & Formativa \\
\hline $\begin{array}{c}\text { Criação e desenvolvimento do } \\
\text { projeto }\end{array}$ & Gerencialista & Consultiva \\
\hline Objetivo do projeto & Assistencial & Autonomia \\
\hline
\end{tabular}

Fonte: Silva (2013)

\section{UM PROJETO VISIONÁRIO}

Em 2 de março de 1982, as professoras Neusa Mendes Guedes e Lúcia HisakoTakase Gonçalves apresentaram à UFSC uma proposta para desenvolver atividades de ensino, pesquisa e extensão voltadas à pessoa idosa. A Portaria n. 356/GR/82 designou a professora Lúcia para prestar assessoria técnica ao NETI, criado oficialmente em 3 de agosto de 1983, pela Portaria n. 045/GR/83 (RED LATINOAMERICANA DE GERONTOLOGIA - RLG, 2004).

Em entrevista, uma das fundadoras revelou ser uma “visão futurista”. Na época, não se podia chegar ao reitor e dizer "tenho uma visão futurista”, mas ela “já sabia”. Frutuoso (1999) afirma que as universidades da terceira idade surgiram com força no Brasil somente em 1990, e a dupla de professoras da UFSC pensou no tema quase dez anos antes. O Professor Schuch (1997, p.146) afirma que a preocupação com a terceira idade “[...] praticamente não existia [...] em 1985".

Em 1982, as professoras Neusa e Lucia fizeram um levantamento das aspirações da população idosa, 


\section{Extensio $\mid$ Artigo}

com uma amostra de idosos vinculados à UFSC e de idosos residentes próximos à universidade, com a colaboração dos alunos do Colégio de Aplicação e do Barddal. Esse levantamento motivou o surgimento do Grupo de Convivência 5 de maio, para reflexão sobre os assuntos de pessoas idosas e troca de experiências (GUEDES, 1997).

Uma das entrevistadas afirma que, no início, as pessoas não tinham muita consciência sobre o tema, e a universidade não tinha muito espaço físico. Foi pela persistência e ajuda de voluntários, futuros alunos do NETI ("não alunos da UFSC", ressalta), e de uns poucos professores que a ideia desabrochou. "Aos idosos do Grupo 5 de Maio o NETI deve sua existência [...]. Eles aceitaram nossos apelos e jamais se queixaram das dificuldades que lhes eram apresentadas" (GUEDES, 1997, p.25). Muitos desses alunos tornaram-se multiplicadores dos conhecimentos adquiridos, cada um conforme sua possibilidade.

LRG (2004) corrobora com a ideia de construção do núcleo por meio de uma ação conjunta: a formação da equipe do NETI surgiu de um trabalho de alunos, professores e funcionários de diversos setores da UFSC e membros da comunidade, a maioria voluntária. As discussões buscavam abranger temas gerontológicos e o fortalecimento da ideia de construir um modelo catarinense de intervenção na área.

Em relação à fundação do NETI, apesar de estar documentado que “[...] a rejeição do assunto (idosos) era presente em autoridades universitárias" (GUEDES, 1997, p.24) e de haver relatos de diversas lutas para conseguir algum espaço, um dos entrevistados remonta ao começo, de outro modo:

[...]foi difícil? Sabe de uma coisa? Eu não vou dizer, às vezes as pessoas dizem isso, eu digo assim: olha, tenho 50 anos de vida profissional, alguém diz assim: seu lattes é quilométrico. Claro, 50 anos, se eu não tivesse feito alguma coisa, não era justo estar aqui. Então eu acho que foi uma obrigação. Como professora de uma universidade eu tinha que fazer ensino, pesquisa e extensão. Eu fiz o melhor que eu pude nestas três funções. E me aposentei e ganhei uma medalha de amiga da UFSC. Adorei também de ter sido reconhecida. Então eu diria que deu certo. Uma ideia que tocou pra frente e deu certo (2012).

Dessa forma, nas entrevistas, parece que as coisas foram naturais. É perceptível o carinho que as pessoas têm ao falar do trabalho, e isso aparece nos quatro entrevistados. A história do NETI foi de acertos, erros e recomeços. Quando foi criado, havia poucos recursos para os idosos, que sofriam os efeitos da marginalização social. Os trabalhos desenvolvidos contribuíram para discussão sociopolítica da questão, muitas vezes incentivando a mobilização de outras entidades para ação conjunta. Desde seu primeiro momento de existência, o NETI sempre incluiu a participação da pessoa idosa em seus projetos. Um dos alunos participantes colocou que, muitas vezes, o processo de marginalização pode vir também por parte do próprio idoso: ele se põe à margem, sente-se sozinho e se recolhe ainda mais por isso. Mas no NETI, já se testemunhou muitas vezes "uma transformação muito grande" em alguns colegas que chegam para fazer um curso, mais tímidos, calados, e que, ao finalizar, com o passar do tempo, está uma pessoa mais comunicativa, que expressa sua opinião, se aceita e, portanto, aceita os outros.

Em 1984 foram iniciadas as atividades de Educação Permanente, os cursos de extensão para a comunidade. Somente em 1985, o Núcleo começou a contar com funcionários administrativos, e em 1987 havia o envolvimento de nove departamentos da UFSC. Um dos entrevistados explicou que a questão do espaço e de recursos sempre foi a mais difícil: são conquistas que se alcançam, mas que são lentas. Não havia, por exemplo, servidores técnico-administrativos com a lotação NETI. Atualmente, são dois. Ainda é pouco, a maioria das pessoas que atendem no NETI é voluntária, o que é um ponto forte, pela questão da mobilização, mas, ao mesmo tempo, fragiliza a estrutura e os projetos, pela questão da continuidade e permanência.

O NETI antecipou-se ao MEC na preocupação com a questão social da velhice, sugerindo a UFSC que 
incluísse cadeiras de conhecimento gerontológico em alguns de seus cursos de graduação.

Em 1989 surge o Grupo de Estudos de Gerontologia, visando conhecer o interesse e disponibilidade dos idosos para atividades de educação continuada, demonstrando o comprometimento com a questão da velhice. Esse grupo influenciou a criação do curso de Formação de Monitores da Ação Gerontologia em 1990, que foi submetido ao Conselho de Ensino, Pesquisa e Extensão da UFSC e aprovado na integra, por meio do Parecer n. 028/CEP/90. Esse curso é uma atividade de Extensão Universitária de longa duração, atualmente, quatro semestres, que "[...] qualifica pessoas idosas em gerontologia ao proporcionar o desenvolvimento de novos conhecimentos e ao estimular a prática do voluntariado na comunidade" (NETI, 2012). Conforme um dos entrevistados, aprende-se sobre o processo de envelhecimento, antropologia, sociologia, filosofia, noções de saúde, direito, gerontologia e psicologia e, ao final do curso, o aluno faz o trabalho de conclusão de curso, que é uma ação multiplicadora. Muitos projetos já foram desenvolvidos dentro e fora do NETI por alunos do curso de monitores. O CENETI, por exemplo, foi criado em 1990 por iniciativa dos alunos.

Entre 1982 a 1990, além de inserir a questão social do idoso na universidade, o NETI transformou a mentalidade da época em relação à velhice. Os idosos reaprenderam a ocupar o seu espaço e a interagir com as outras gerações como agentes de transformações sociais. A partir de 1990, firma-se a questão social da velhice, desenvolvendo ações integradas com os grupos representativos da comunidade, organismos públicos e privados no trabalho preventivo de possíveis patologias do envelhecimento (RLG, 2004).

Atualmente o NETI tem diversas parcerias: a UFSC tem um assento no Conselho Estadual do Idoso, e a representação é o NETI. No Conselho Municipal do Idoso, o NETI não tem assento, mas há professores e alunos que participam. O Serviço Social do Comércio (SESC) está presente desde o início da história do NETI, que atualmente mantém uma troca recíproca de ajuda com o núcleo, em questão de palestras, de eventos em conjunto, etc. Com a Associação Nacional de Gerontologia (ANG), bem como sua sessão de Santa Catarina, são desenvolvidos trabalhos em conjunto porque os profissionais que trabalham no NETI geralmente são associados. A Federação Catarinense dos Municípios (FECAM) tem um convênio assinado com o NETI para capacitação de pessoas. Esse convênio está inserido dentro de um projeto do NETI: o Projeto de Intercâmbio Comunitário (PIC) em Gerontologia. Outra parceria é com a Associação de Pais e Amigos dos Excepcionais (APAE), que já é antiga e surgiu de uma motivação pessoal, porque um dos colaboradores do NETI tinha um membro da família na APAE.

Um grupo de estudos sobre envelhecimento e deficiência foi iniciado em 2012, e há planos de ampliá-lo em 2013: NETI, APAE, alguns professores da universidade e outros grupos de atuação do Estado. Há poucos estudos sobre o tema, e o grupo pretende ajudar a preencher essa lacuna.

Diversos centros e fundações da UFSC cedem espaço ao NETI, já que as instalações são insuficientes para a quantidade de cursos ofertados. Além das fundações, o Departamento Artístico Cultural da UFSC (DAC) cede espaço ao grupo de teatro e outras manifestações artísticas que ali acontecem. No Centro de Desportos (CDS), há diversas atividades físicas voltadas para idosos, que são atividades chamadas "em consonância" com o NETI. O Hospital Universitário (HU) também é parceiro: nele acontece o grupo de Alzheimer e também são encaminhados os idosos para atendimento no HU, onde se tem um atendimento diferenciado no que se refere à questão da saúde.

Um dos entrevistados destacou que o HU tem uma relação forte com o NETI, porque é muito importante, para uma cidadania plena, um atendimento de saúde digno. Demo (1995) coloca que, para uma cidadania emancipada, é necessária a autossustentação: antes de falar em reivindicação dos direitos, é preciso que a pessoa esteja bem. Assim, no HU, foi desenvolvido um grupo chamado Núcleo Interdisciplinar de 
Gerontologia (NIPEG), que trabalha dando assistência aos idosos que necessitam. Os núcleos se conversam, mas são separados. O NETI assumiu com força a vertente da educação, porque, se ficasse apenas no social e na saúde, iria acabar “descambando mais pro assistencialismo" (ENTREVISTADO A, 2012).

Em relação à educação, há turmas para diversos níveis e necessidades de aprendizado, inclusive a educação básica, com parceria com a Prefeitura Municipal de Florianópolis (PMF), através da Educação de Jovens e Adultos (EJA). A parceria foi realizada, porque se percebeu que o aluno que concluía seu processo de alfabetização desejava receber o certificado formal, fornecido pela EJA. Um entrevistado falou que alguns alunos sentiam-se inibidos de falar que estavam no curso de alfabetização, e atualmente o projeto chama-se leitura e escrita. Conta com aulas três dias por semana, e, nos outros dois dias, há também bolsistas que se dispõem a dirimir dúvidas e desenvolver trabalhos com a turma.

A Sociedade Brasileira de Geriatria e Gerontologia (SBGG) também é parceira em eventos. No setor privado, a Videoteca é uma empresa parceira, que fornece os DVDs para o curso de Cinedebate, além de promover encontros no cinema - já foram realizadas algumas sessões de cinema nos cinemas da cidade com alunos, em horário especial, fora do mais comercial, para assistir determinado filme de forma gratuita, promovido pela empresa.

O Cinedebate em Gerontologia é um curso desenvolvido em quatro semestres que incentiva o debate e a reflexão do processo de viver e envelhecer através de personagens retratados em filmes. O curso é muito apreciado pelos participantes, que expressam nostalgia quando ele está próximo do fim.

Como o objetivo da cidadania e de um bom projeto de extensão é a sustentabilidade, ou seja, a percepção de que os participantes possam andar com as próprias pernas e utilizar e multiplicar o aprendizado em seu cotidiano e para ajudar as outras pessoas, um dos entrevistados contou um fato interessante que ocorreu em 2012, junto à formatura do Cinedebate: muitos dos formandos estavam tristes pelo encerramento do curso, que tem uma duração específica. Para consolá-los e estimulá-los, a facilitadora apresentou aos formandos dois ex-alunos, já formados, que criaram seus próprios cineclubes e continuaram encontrando pessoas e promovendo debates e que, inclusive, convidaram os formandos para participarem. É interessante perceber que diversas pequenas iniciativas podem fazer uma diferença na atitude das pessoas.

Em 1991 o NETI atinge um patamar de experiências acumuladas com a criação do Curso de Especialização em Gerontologia e com a coordenação do I Encontro Nacional de Estudantes de Terceira Idade e coordenação do I Fórum de Coordenadores de Ações de Educação na 3a Idade (RLG, 2004). Em entrevistas, relatou-se que foi trabalhoso articular um curso de pós-graduação que não fosse vinculado a um centro ou departamento específico, e sim a um núcleo, mas que valeu a pena: vários departamentos estão envolvidos no projeto, assim como alunos de todas as áreas se interessam pela especialização, holística e interdisciplinar, como deve ser um trabalho na área de gerontologia. É o único curso do NETI que exige nível superior e que não tem idade mínima. As demais atividades do NETI são para pessoas com 50 anos ou mais.

O entrevistado ressalta, entretanto, que o trabalho não deve parar na especialização: o NETI está dentro de uma universidade e é um grande laboratório, deveria ser mais explorado no desenvolvimento de pesquisas que beneficiariam seu público, que a cada dia irá aumentar. Para ele, o NETI é mais reconhecido fora do que dentro da universidade - opinião compartilhada pelos demais entrevistados. Afirmou que o NETI tem que se fortalecer, pois atualmente "ele está escondidinho, ele não tá barulhento, ele não está visível". Antes, ele não era visível no organograma.

Hoje em dia NETI já está penduradinho no organograma da universidade. Ele tá visível. Você abre o catálogo, o site da universidade, você vê algum lugar, NETI tá lá pendurado. Então já está visível. Mas, só que não está, aquilo que a Neusa 
fazia, divulgava, fazia barulho. Uma coisa é visível no organograma, outra coisa é visível ao público. Não público externo, porque público externo tem: você diz: ah, NETI da universidade? Mas é visível internamente na universidade. Quando eu digo visível, tem que ser visível pela sua importância (ENTREVISTADO A, 2012).

Nesse sentido, o entrevistado ressalta que a atividade política, de manifestar-se sempre à parte estratégica da universidade, o "fazer barulho" é também importante, assim como divulgar mais pesquisas. Em sua opinião, se deveria fazer um esforço conjunto de juntar bons doutores, engajados na temática da terceira idade e criar um curso de mestrado em gerontologia, o que fortaleceria o NETI e todos que dele participam, além daqueles que são participantes potenciais, mas ainda não comparecem. Esse benefício viria com a qualidade e divulgação de mais pesquisas científicas na área.

Para outro entrevistado, apesar de ainda ter muito a se trabalhar na questão de divulgação e de conscientização do entorno, iniciativas interessantes ocorreram nos últimos anos. Um exemplo é o curso de política e envelhecimento, que surgiu da demanda dos próprios estudantes:

[...] surgiram da necessidade que os nossos idosos sentiram de aprender mais sobre o que é política, de que política nós estamos falando, sobre o ser político, né, não se refere em nenhum momento à política partidária. E como é que a pessoa idosa pode usar esses conhecimentos na sua prática (ENTREVISTADO B, 2012).

Uma aluna que já participou de vários cursos do NETI, inclusive desse curso de política, em 2012 candidatou-se à Presidente do Conselho Municipal do Idoso de Florianópolis. Outro participante do curso de política e do curso de monitores participou do intercâmbio e atualmente é conselheiro no Conselho Municipal do Idoso.

No segundo semestre de 2012, dando sequência a essa linha de cursos, foi ofertado o curso Previdência e Cidadania, cujo objetivo é dialogar e orientar sobre os direitos a aposentadorias especiais, além de explicitar outros benefícios garantidos pela constituição e por leis especiais aos cidadãos, principalmente aos idosos. Além das questões previdenciárias, o conteúdo programático incluía noções de Gestão Pública, Ética e Cidadania, Lei de Informação, entre outros. Todos os alunos que participaram do curso manifestaram o desejo de continuá-lo, e, em 2013, ele está sendo ofertado novamente.

Desde 2011 o NETI está sobre a coordenação atual. Nesse período, foi criado o Comitê Assessor do NETI, de caráter consultivo para apoio pedagógico composto pala coordenadora, professores em exercício e aposentados da UFSC que desenvolvem projetos dentro do NETI. O comitê de caráter consultivo é importante para a discussão de questões e novos projetos de forma mais participativa. Entretanto, caberia dentro desse comitê representações dos alunos, por exemplo, cada curso poderia eleger um representante, para participar de reuniões e definir rumos para o núcleo.

\section{CONCLUSÕES}

Como um projeto pioneiro, o NETI luta desde o início por legitimidade, sendo muito reconhecido em como referência para instituições que trabalham com a terceira idade em Santa Catarina e no Brasil. Iniciou pequeno, mas sempre com muita vontade e, atualmente, já com um espaço próprio dentro da UFSC, continua sua luta por espaço e reconhecimento dentro da universidade.

Através de observação, entrevistas e pesquisa bibliográfica e documental, buscou-se conhecer a história e as práticas do núcleo, para caracterizá-las, segundo a perspectiva do compromisso social. Percebe-se que, 
desde o início, o núcleo teve as características de um posicionamento socialmente comprometido: a base da construção foi o diálogo e o convite a "fazer junto". Muitas vezes, e não apenas nas entrevistas, é percebida a preocupação de que os alunos realmente utilizem seus conhecimentos e os repliquem na sociedade.

Em relação à metodologia, a maioria dos cursos busca uma posição formativa. A intenção (objetivo) dos projetos é a autonomia, não adotando uma postura somente assistencialista. Em relação à criação e desenvolvimento dos projetos, apesar de o comitê consultivo não ter representantes estudantis, há evidências - além de relatos - de que os participantes têm voz ativa, desde o início, e que participam da construção dos projetos, e alguns alunos já se tornaram professores de outros cursos.

Assim, o NETI é um espaço muito importante para a comunidade, vindo, desde a sua criação, de um processo de participação ativa de seus membros, da vontade de colocar o idoso em uma posição representativa no âmbito da universidade e na sociedade, e que, junto a outras instituições parceiras, já conseguiu algumas conquistas. Entretanto, como toda instituição, o núcleo precisa recriar os espaços de comunicação e participação, não esquecer seu propósito inicial, mas seu espaço dentro do ambiente acadêmico, para que todos o reconheçam como a referência em gerontologia que ele é.

\section{REFERÊNCIAS}

ASSOCIAÇÃO INTERNACIONAL DAS UNIVERSIDADES DA TERCEIRA IDADE (AIU3A, França). Historique. Disponível em: <http://aiu3a.com/HISTORIQUE.html>. Acesso em: 03 Out. 2012.

BANCO MUNDIAL. Envelhecendo em um Brasil mais velho. 2011. 64 p. Disponível em: <http://siteresources.worldbank.org/BRAZILINPOREXTN/Resources/3817166-1302102548192/Envelhecendo_Brasil_ Sumario_Executivo.pdf>. Acesso em: 08 ago. 2012.

BECKER, Howard S. Métodos de Pesquisa em Ciências Sociais. 3a ed. São Paulo: Editora Hucitec, 1997.

BRASIL. Constituição da República Federativa do Brasil. Constituição (1988). Disponível em <http:// www.planalto.gov.br/ccivil_03/constituicao/constitui\%C3\%A7ao.htm> Acesso em 10 Ago. 2012.

. Ministério da Saúde. Governo Federal. Futuro. Disponível em: $<$ http://portal.saude.gov.br/portal/saude/visualizar_texto.cfm?idtxt=34054\&janela=1>. Acesso em: 02 Ago. 2012.

CHAUÍ, Marilena. A universidade pública sob nova perspectiva. Revista Brasileira de Educação, Rio de Janeiro, n. 24, Dec. 2003. Disponível em: <http://www.scielo.br/scielo.php?script=sci_arttext\&pid=S1413-24782003000300002\&lng=en\&nrm=iso>. Acesso em 03 out. 2012.

CHIZZOTTI, Antônio. Pesquisa em Ciências Humanas e Sociais. 2. ed. São Paulo: Cortez, 1995.

CRUZ, Breno de Paula Andrade et al. Extensão Universitária e Responsabilidade Social: 20 Anos de Experiência de uma Instituição de Ensino Superior. In: XXXIV ENANPAD. 2010, Rio de Janeiro, 2010. Disponível em: <http://ebape.fgv.br/sites/ebape.fgv.br/files/extensao_universitaria.pdf>. Acesso em: 10 ago. 2011. 
DAL RIO, Maria Cristina. Construção de Novas Formas de Sociabilidade no Processo de Envelhecimento e na Velhice. In: DAL RIO, Maria Cristina; MIRANDA, Danilo Santos de. Perspectiva Social do Envelhecimento. São Paulo: Secretaria Estadual de Assistência e Desenvolvimento Social: Fundação Padre Anchieta, 2009. p. 11-27.

DANIEL, Fernanda. O conceito de velhice em transformação. Interações: Sociedade e Novas Modernidades. Coimbra: Instituto Superior Miguel Torga. n. 10, p. 113-122. Abr. 2006. Disponível em: < http://www. interacoes-ismt.com/index.php/revista/article/view/179/185>. Acesso em 13 Set. 2012.

DEBERT, Guita Grin. A invenção da Terceira Idade e a rearticulação de formas de consumo e demandas políticas. ANPOCS, 1996. GT Cultura e Política da ANPOCS. Disponível em:

<http://www.anpocs.org.br/portal/publicacoes/rbcs_00_34/rbcs34_03.htm>. Acesso em: 02 ago.2012

. Envelhecimento e Curso da Vida. Revista Estudos Feministas, v. 15, n. 1, p. 120-128, 1997. Disponível em: < http://www.ieg.ufsc.br/admin/downloads/artigos/12112009-093723debert.pdf>. Acesso em 02 jul. 2012.

. Gênero e Envelhecimento: Os Programas para a Terceira Idade e o Movimento dos Aposentados. Revista Estudos Feministas, v. 2, n. 3, p. 33-51, 1994. Disponível em: < http://www.periodicos.ufsc.br/ index.php/ref/article/view/16288/14829>. Acesso em 02 jul. 2012.

DEMO, Pedro. Cidadania tutelada e cidadania assistida. Campinas: Ed. Autores Associados, 1995.

FREIRE, Paulo. Educação e Mudança. Rio de Janeiro: Paz e Terra, 1979.

FRUTUOSO, Dina. A Terceira Idade na Universidade. Rio de Janeiro: Ágora da Ilha, 1999.

GOERGEN, Paulo. Universidade e Compromisso Social. In: RISTOFF, Dilvo; SEVEGNANI, Palmira (org.). Universidade e Compromisso Social: Brasília, 25 e 26 de agosto de 2005. Brasília: Instituto Nacional de Estudos e Pesquisas Educacionais Anísio Teixeira, 2006. p. 65-95. (Coleção Educação Superior em Debate; v.4).

GUEDES. Neusa Mendes. A construção de um caminho. In: GRÜNEWALD, Virginia (Org.). NETI: A Construção de um Caminho na Gerontologia. Florianópolis: Copyflo, 1997. p. 21 - 28.

KARKOTLI, Gilson. Responsabilidade Social Empresarial. Petrópolis, RJ: Vozes, 2006.

LAKATOS, Eva Maria. MARCONI, Marina de A. Metodologia do trabalho científico. $4{ }^{\text {a }}$ ed. São Paulo, 1995.

MINAYO, Maria Cecília de Souza (Org.). Pesquisa Social: teoria, método e criatividade. Petrópolis: Vozes, 2002.

NASRI, Fabio. O envelhecimento populacional no Brasil. Einstein, São Paulo, v. 6 (supl.1), p.S4-S6, 2008. Disponível em: <http://apps.einstein.br/revista/arquivos/PDF/833-Einstein\%20Suplemento\%20v6n1\%20 pS4-6.pdf>. Acesso em: 02 ago. 2012.

NETI. UFSC. Apresentação. Disponível em <http://neti.ufsc.br/?s=miss\%C3\%A3o\&x=0\&y=0>. Acesso em: 10 jan. 2013. 
NETI. UFSC. Atividades. Disponível em: < http://neti.ufsc.br/atividades/>. Acesso em 20 dez. 2012.

NOGUEIRA, Maria das Dores Pimentel (org.) FORUM NACIONAL DE PRÓ-REITORES DE EXTENSÃO

DAS UNIVERSIDADES PUBLICAS (BRASIL). Extensão universitária: diretrizes conceituais e políticas. Belo Horizonte: UFMG, PROEX, 2000.

NOVO, Luciana Florentino; MELO, Pedro Antônio de. Universidade Empreendedora: fortalecendo os caminhos para a responsabilidade social. In: MELO, Pedro Antônio de; COLOSSI, Nelson (org.) Cenários da Gestão Universitária na Contemporaneidade. Florianópolis: Insular, 2004. p.17-35.

PACHECO, Eliezer Moreira. Debate Universidade e Compromisso Social. In: RISTOFF, Dilvo; SEVEG

NANI, Palmira. Universidade e Compromisso Social: Brasília, 25 e 26 de agosto de 2005. Brasília: INEP, 2006. p. 103-244. (V.4).

PLANO Nacional de Extensão Universitária. Ilhéus: Editus, 2001.

RLG. Red Latinoamericana de Gerontologia (Santiago de Chile). Antecedentes del Núcleo de Estudios de Tercera Edad-NETI. 2004. Disponível em: <http://www.gerontologia.org/portal/about.php>. Acesso em: 01 jan. 2013.

RICCI, Natália Aquaroni et al. Interdisciplinaridade na gerontologia: uma revisão da literatura. Revista Kairós: gerontologia, São Paulo, 9(2), p.19-37, dez. 2006. Semestral. Disponível em: <http://www4. pucsp.br/pos/gerontologia/downloads/Kairosv9_n2.pdf>. Acesso em: 08 ago. 2012.

RISTOFF, Dilvo. A Universidade Brasileira Contemporânea: Tendências e Perspectivas. In: MOROSINI, Marilia (org.). A Universidade no Brasil: conceitos e modelos. Brasília: Instituto Nacional de Estudos e Pesquisas Educacionais Anísio Teixeira, 2006. p. 37-52.

SANTOS, Boaventura de Sousa. A Universidade no Século XXI: Para uma Reforma Democrática e Emancipatória da Universidade. In: SANTOS, Boaventura de Sousa; ALMEIDA FILHO, Naomar de. A Universidade no Século XXI: Para uma Universidade Nova. Coimbra: Almedina, 2008. p. 13104.

SCHUCH, Vitor Francisco. O Despertar para a terceira Idade no NETI. In: GRÜNEWALD, Virginia (Org.). NETI: A Construção de um Caminho na Gerontologia. Florianópolis: Copyflo, 1997. p. 141 147.

TENÓRIO, Fernando Guilherme. Gestão Social: uma réplica. In: RIGO, Ariádne Scalfoni; et al. Gestão Social e Políticas Públicas de Desenvolvimento: Ações, Articulações e Agenda. Recife: UNIVASF, 2010.

SILVA, Flora Moritz da. Universidade e Compromisso Social: a Prática da Universidade Federal de Santa Catarina. 2010. 168 f. Monografia (Bacharel em Administração) - UFSC, Florianópolis, 2010.

SILVA, Flora Moritz da. Universidade e Compromisso Social: a Prática da Universidade Federal de Santa Catarina no Núcleo de Estudos da Terceira Idade. 2013. Dissertação (Mestrado em Administração) - UFSC, 
Florianópolis, 2010.

VERAS, Renato Peixoto; CALDAS, Célia Pereira. Promovendo a saúde e a cidadania do idoso: o movimento das universidades da terceira idade. Ciência saúde coletiva, Rio de Janeiro, v. 9, n. 2, Jun. 2004 . Disponível em: <http://www.scielo.br/scielo.php?script=sci_arttext\&pid=S1413-81232004000200018\&lng=en\&nrm=iso>. Acesso em: 13 Set. 2012 